OPEN ACCESS

Edited by:

Caterina Ledda

University of Catania, Italy

Reviewed by:

Begoña Martínez Jarreta, University of Zaragoza, Spain

Siti Munira Yasin

MARA University of Technology,

Malaysia

*Correspondence:

Fang Liu

liufang816@126.com

Specialty section:

This article was submitted to Occupational Health and Safety,

a section of the journal

Frontiers in Public Health

Received: 30 June 2021

Accepted: 17 August 2021 Published: 21 September 2021

Citation:

Song J, Liu F, Li X, Qu Z, Zhang R and Yao J (2021) The Effect of Emotional Labor on Presenteeism of Chinese Nurses in Tertiary-Level Hospitals: The Mediating Role of Job Burnout. Front. Public Health 9:733458. doi: $10.3389 /$ fpubh.2021.733458

\section{The Effect of Emotional Labor on Presenteeism of Chinese Nurses in Tertiary-Level Hospitals: The Mediating Role of Job Burnout}

\author{
Jia Song ${ }^{1}$, Fang Liu ${ }^{1 *}$, Xiaowei $\mathrm{Li}^{1}$, Zhan $\mathrm{Qu}^{2}$, Rongqiang Zhang ${ }^{3}$ and Jie Yao ${ }^{1}$ \\ ${ }^{1}$ School of Nursing, Shaanxi University of Traditional Chinese Medicine, Xianyang, China, ${ }^{2}$ School of Nursing, Health Science \\ Center, Xi'an Jiaotong University, Xi'an, China, ${ }^{3}$ School of public health, Shaanxi University of Traditional Chinese Medicine, \\ Xianyang, China
}

Background: Employees who are physically present but work insufficiently because of illness are deemed as having presenteeism. In the health care setting, the issue has taken on greater importance because of the impairment of the physical and mental health of nurses and the nursing safety of the patients. According to the Job Demand-Resource Model, burnout may link emotional labor with presenteeism. Thus, this study analyzed the role of burnout as a mediating factor between the three types of emotional labor strategies and presenteeism among nurses in tertiary-level hospitals.

Methods: A cross-sectional study of 1,038 nurses from six Chinese hospitals was conducted. The questionnaires, including the 14-item emotional labor strategies scale, 22-item Maslach Burnout Inventory scale, 6-item Stanford Presenteeism Scale, and items about demographic characteristics and work-related factors, were used to collect data. A multivariable linear regression was used to predict work-related factors and investigate the correlation of emotional labor, burnout, and presenteeism. The structural equation model was implemented to test the mediating effects of job burnout.

Results: The results of the study showed that the average presenteeism score of the participants was 14.18 (4.33), which is higher than in Spanish, Portuguese, and Brazilian nurses. Presenteeism was explained by $22.8 \%$ of the variance in the final model in multivariable linear regression $(P<0.01)$. Presenteeism was found to be positively correlated with surface acting, emotionally expressed demands, deep acting, emotional exhaustion, depersonalization, and low personal accomplishment $(P<0.01)$. Notably, presenteeism was negatively correlated with deep acting $(P<0.01)$. In addition, burnout partially mediated the correlation between emotionally expressed demands, deep acting, and presenteeism with a mediatory effect of 24 and $63.31 \%$ of the total effect. Burnout completely mediated the association between surface acting and presenteeism, a mediating effect of $86.44 \%$ of the total effect. 
Conclusions: The results of this study suggested that different emotional labor strategies affect presenteeism, either directly or indirectly. Nursing managers should intervene to reduce presenteeism by improving the ability of the nurses to manage emotions, thereby alleviating burnout.

Keywords: presenteeism, emotional labor, burnout, nurses, China

\section{INTRODUCTION}

Presenteeism has become a common phenomenon in the workplace which is defined as impaired productivity or performance while ill but still working (1-4). The concept has been of great interest for over two decades. More than $80 \%$ of healthcare providers and physicians in England and Norway will attend work despite ill health $(5,6)$. Furthermore, more than $70 \%$ of Danish core workers had gone to the workplace while ill (7). Additionally, one cross-sectional study reported that $74 \%$ of Chinese employees must work despite being ill; the frequency of presenteeism is almost once a month (8). Previous studies in Turkey, Korea, and the United States had demonstrated the high prevalence and factors of presenteeism, including among doctors and nurses (9-11). Nurses may experience up to four times as much presenteeism as other health or welfare workers in Sweden (12) because of the apparent characteristics of nursing work, such as shift work, an increased workload, low replaceability, and extended working time (13-16). The presenteeism phenomenon may impair the physical and mental health of nurses $(8,17)$ and reduce health-related productivity and increased economic costs $(18,19)$. It has also been shown that presenteeism will compromise patient safety and reduce the work quality of nurses by increasing the risk of patient falls and medication errors and disease transmission (11, 20, 21). Therefore, combating presenteeism behavior may be a key to improve the health productivity of nurses. At present, there is little empirical research on the presenteeism of nurses. This study provided a new way of thinking for nursing managers to reduce the presenteeism of nurses.

Managers have taken notice of the link between emotional labor, burnout, and presenteeism. Nurses provide professional medical services as well as face-to-face communication and listening to the concerns of patients. Nursing is an emotionally labor-intensive profession. Emotional labor refers to individual efforts, plans, management of emotional expression, or bodily display in response to organizational demands in the workplace (22). Job burnout is a mental health injury state in which employees suffer from chronic work-related stress (23). The concept of burnout in three dimensions, including emotional exhaustion, depersonalization, and low personal accomplishment, as proposed by the study of Maslach and Jackson is generally accepted (24). The characteristics of burnout are emotional exhaustion, overextended alienation from the job, and a sense of perceived incompetence in positions $(23,24)$.

The study of Grandey et al. presented two main emotional labor strategies, namely, surface acting and deep acting; other studies have adopted this approach $(25,26)$. Surface acting is not just suppression but also the regulation of emotion with an expression that matches the expectations of the organization. Deep acting occurs when employees keep inner feelings consistent with their displayed expression (22). This is an antecedent-focused emotional regulation (reappraisal and situation modification), while surface acting is a responsefocused emotion regulation (physiological change and expression suppression) (27). According to the meta-analytic structural model of Kammeyer, deep acting is a positive predictor of job performance, while surface acting predicted burnout negatively (28).

Investigators have recently examined the correlation between emotional labor and job burnout, emotional exhaustion, jobrelated stress, depression symptoms, customer orientation, and presenteeism (29-33). Previous research also has demonstrated that burnout, job-related anxiety, depression, and emotional labor can all be risk elements for presenteeism (16, 30, 32-34). Based on these discussions, job burnout may have a direct or indirect mediating effect on emotional labor and presenteeism.

Job Demand-Resource Model and Emotional Labor theory are applied to understand the correlation between emotional labor, job burnout, and presenteeism. The Job Demand-Resource Model proposes that job demand is the important antecedent of in-role performance through the mediating effect of the emotional exhaustion component of burnout, i.e., cognitive and emotional fatigue (35-37). Job demands are described as work-related aspects requiring sustained physical or mental effort with specific physical or psychological costs, including high work stress, emotional demands, and undesired working conditions (38). In-role performance is defined as meeting organizational targets and practical functions (35). The existing body of research on high job demands suggests that they are associated with occupational burnout (39) and presenteeism (40). At the same time, emotional display required by the organization is a significant job demand, especially for nurses (41). Based on previous studies and the foundation of the Job Demand-Resource Model, we proposed the hypothesis that emotional labor affects presenteeism through the mediating effect of job burnout.

According to the Emotional Labor theory, emotional labor affects individual and organization levels (42). Moreover, Grandey proposed that emotional labor, involving both surface acting and deep acting, is linked to individual wellbeing, involving both job satisfaction and job burnout, and organizational well-being, involving both performance and withdrawal behavior $(22,27)$. In addition, a past study demonstrated how Korean nurses associate emotional labor with presenteeism (30). However, few studies have explored 


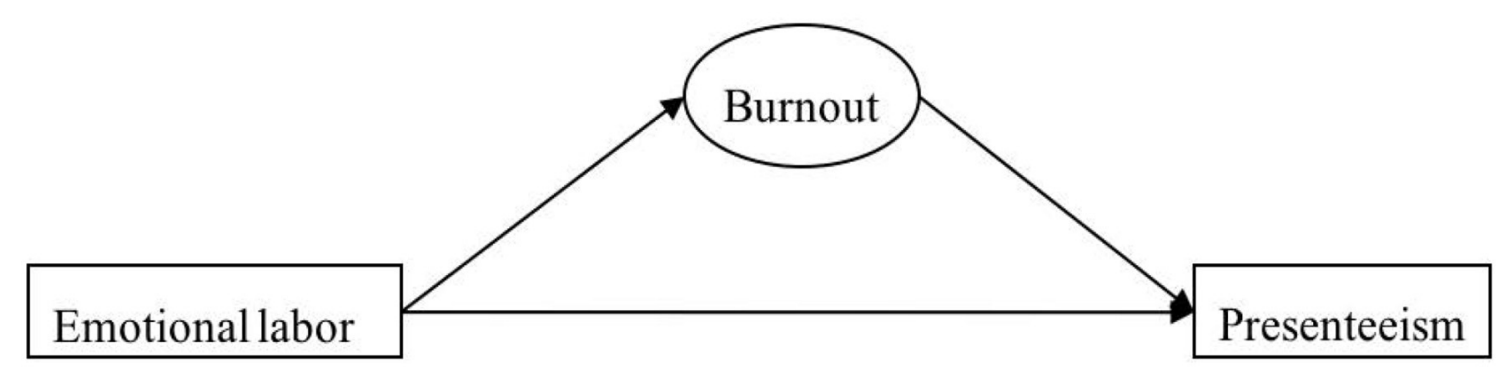

FIGURE 1 | The hypothesized model.

these different emotional regulation strategies, which have other effects.

Based on the Job Demand-Resource Model and Emotional Labor Theory, this study examined the correlations between emotional labor, burnout, and presenteeism and the mediating effect of burnout and the relationship between emotional labor and presenteeism in mitigating the low productivity of nurses. It is meaningful to understand how emotional labor affects presenteeism. Figure 1 depicts the hypothesized model.

\section{METHOD}

\section{Setting and Sample}

Convenience sampling was used to recruit from the six tertiary hospitals in Shaanxi province, China. Six hospitals with similar hospital grades as designated by the Ministry of Health were selected. For a convenience sample, nurses with a professional certificate, informed consent, and voluntary involvement in this study were included. Excluded were nurses who had worked for less than a year and nurses who were on leave for various reasons during the investigation.

The study of Thompson recommended that 10-15 times of questionnaire items count the sample size for the structural equation model (43). The self-administered questionnaire consisted of 42-items, including 14 emotional labor items, 22 job burnout items, and 6 presenteeism items. The total sample size involved 630 participants. However, the sample size was expanded by $20 \%$ because of incomplete questionnaires, resulting in a final sample size of 756 participants. A total of 1,054 nurses were recruited.

\section{Ethical Approval}

The nurses voluntarily chose to participate in this study and were free to drop out. The electronic information submitted was anonymous, and only the researchers had access to data. The Ethics Committee of the Affiliated Hospital of Shaanxi University of Traditional Chinese Medicine, Shaanxi Province, China approved this study.

\section{Data Collection}

The study was carried out from October to December 2020. A structured questionnaire with four parts was distributed to all participants, covering sociodemographic information, emotional labor, job burnout, and presenteeism. The participants were volunteers and we assured them that all their information would be kept confidential. Before the questionnaire was issued, we contacted the nursing departments of hospitals, introduced the purpose of this study to obtain permission, and discussed the survey time and the number of respondents. Two trained graduate students went to the six hospitals and conducted the field survey from October to December 2020. The nurses were informed of the purpose, significance, and independent completion of the survey. The questionnaires were completed on-site with the participation of the nursing managers of each hospital and the supervision of the two graduate students. WeChat (a popular social networking tool in China) was utilized to conduct the electronic questionnaire. Those who chose the same option in questionnaires and those who missed $>10 \%$ of items were excluded. After filtering, 1,038 questionnaires were included in the subsequent analysis with a response rate of 98.48\%.

\section{Data Analysis}

The analysis of the collected data was carried out using SPSS 26, Excel, and AMOS 23.0 software (both by IBM, Armonk, NY, USA). First, the demographic and work-related characteristics of the participants were determined using descriptive statistics. Pearson's correlation coefficients were used to calculate the correlation between all variables. Multivariable linear regression was used to predict work-related factors. Second, to test the validity and calculate the Cronbach alpha coefficient to estimate internal consistency, confirmatory factor analysis was conducted using AMOS. Third, to explore the link between the three emotional labor strategies, burnout, and presenteeism, the structural equation model was implemented and the mediating effects of job burnout were tested. The maximum likelihood method was used to confirm interrelationships and parameters between the variables in the structural equation modeling (SEM). We assessed the adequacy by the likelihood ratio $\left(\chi^{2} / d f\right)$, adjusted goodness of fit index (AGFI), Tucker-Lewis fit index (TLI), comparative fit index (CFI), standardized root mean square residual (SRMR), and root means the square error of approximation (RMSEA). An RMSEA $<0.05$, SRMR $<0.08$, and 
$\chi^{2} / d f<3$ indicated good model fit (44), while the other indices such as AGFI $>0.90$ can be construed as an acceptable fit (45).

\section{Measurements}

\section{Sociodemographic Characteristics}

The demographic questionnaire included gender, age in years, marital status, professional title, employment status, monthly income (RMB, yuan), and weekly overtime. The criterion age was categorized as $20-30,30-40,40-50$, and $>50$ in years. Marital status was categorized as unmarried, married without children, married with children. Professional title was categorized as either nurse, senior nurse, nurse supervisor, or above. Employment Status was categorized as either contractual or permanent. The biggest difference between contractual and permanent status is that the employer may have the right to discontinue the contract after the contract period has expired, while permanent employees work until retirement. Monthly Income (RMB, yuan) was categorized as <3,000 RMB, 3,000-5,000 RMB, > 5,000 RMB. The number of times working overtime per week was categorized as $0,1-2,3-4$, and $>5$.

\section{Emotional Labor Strategies}

The emotional labor strategy scale was used to assess the emotional performance strategies of the nurses in clinical work. As discussed above, the emotional labor strategy scale has two factors which are surface acting and deep acting (46). Based on the Emotional labor strategy Scale, the study of Luo combined the Chinese clinical nursing reality, revised by psychology and nursing professionals, and formed a questionnaire including 3 dimensions with 16 items (47). The Chinese version of the nurse emotional labor strategy scale consists of surface acting (SA, 7 items), deep acting (DP, 3 items), and emotionally expressed demands (EED, 4 items). Emotionally expressed demands refers to when nurses are required to show specific behaviors or expressions to reflect the image of the nurse to be established in the hospital. Each dimension was scored on a Likert- 6 scale. In our study, the values of Cronbach alpha for three subscales were $0.85,0.70$, and 0.812 , respectively. Higher scores indicate nurses experience higher levels of emotional labor.

\section{Maslach Burnout Inventory}

The 22-item self-report Maslach Burnout Inventory (MBI) was used to measure burnout, which consisted of emotional exhaustion (EE, 9 items, depersonalization (D, 5 items), and low personal accomplishment (LPA, 8 items) (24). MBI responses range from 0 (never) to 6 (every day). The nine-item emotional exhaustion subscale mainly evaluates emotional reactions caused by excessive work stress. The five-item depersonalization subscale mainly evaluates stress-induced attitudes and feelings toward the service recipient. The eight-item personal accomplishment subscale mainly describes stress-induced perceptions of the work of oneself. The scale has been established as a reliable and valid measurement in other studies (48-50). In this Study, the Chinese version of the MBI revised by Hua is used (51). Cronbach's alpha for three subscales were $0.9,0.74$, and 0.84 , respectively.
TABLE 1 | Demographic and working characteristics of nurses $(N=1,038)$ and scores of presenteeism.

\begin{tabular}{|c|c|c|c|}
\hline Variable & Category & $N(\%)$ & Mean \pm SD \\
\hline \multirow[t]{2}{*}{ Gender } & Female & $1,012(97.5)$ & $14.18 \pm 4.31$ \\
\hline & Male & $26(2.5)$ & $13.92 \pm 5.11$ \\
\hline \multirow[t]{4}{*}{ Age (years) } & $20-30$ & $598(57.6)$ & $13.88 \pm 4.29$ \\
\hline & $30-40$ & $367(35.4)$ & $14.60 \pm 4.41$ \\
\hline & $40-50$ & $67(6.5)$ & $14.37 \pm 4.01$ \\
\hline & $>50$ & $6(0.6)$ & $15.83 \pm 4.88$ \\
\hline \multirow[t]{3}{*}{ Marital status } & Unmarried & $272(26.2)$ & $13.96 \pm 4.31$ \\
\hline & Married without children & $134(12.9)$ & $13.88 \pm 4.32$ \\
\hline & Married with children & $632(60.9)$ & $14.33 \pm 4.33$ \\
\hline \multirow[t]{4}{*}{ Professional title } & Nurse & $249(24.0)$ & $14.13 \pm 4.64$ \\
\hline & Senior nurse & $543(52.3)$ & $14.00 \pm 4.28$ \\
\hline & Nurse supervisor and above & $246(23.7)$ & $14.61 \pm 4.09$ \\
\hline & Permanent & $88(8.5)$ & $14.19 \pm 4.32$ \\
\hline \multirow[t]{4}{*}{ Weekly overtime } & 0 & 341 (32.9) & $13.53 \pm 4.07$ \\
\hline & $1-2$ & $506(48.7)$ & $14.06 \pm 4.22$ \\
\hline & $3-4$ & $140(13.5)$ & $15.51 \pm 4.65$ \\
\hline & $>5$ & $51(4.9)$ & $15.94 \pm 4.88$ \\
\hline \multirow[t]{2}{*}{ Employment status } & Contract & $950(91.5)$ & $4.08 \pm 4.42$ \\
\hline & Permanent & $88(8.5)$ & $14.19 \pm 4.32$ \\
\hline \multirow[t]{3}{*}{ Monthly income } & $<3,000$ & $92(8.9)$ & $13.58 \pm 4.77$ \\
\hline & $3,000-5,000$ & $627(60.4)$ & $14.30 \pm 4.34$ \\
\hline & $>5,000$ & $319(30.7)$ & $14.10 \pm 4.15$ \\
\hline
\end{tabular}

\section{Stanford Presenteeism Scale}

The Chinese version of the 6-item Stanford Presenteeism Scale (52), produced by the study of Koopman et al. (53), was used to estimate health-related productivity loss. It is a tool for evaluating the loss of productivity or performance due to presenteeism caused by specific health problems (53). Responses for presenteeism ranged from 1 (completely disagree) to 5 (totally agree). Six items make up the SPS-6, containing two dimensions of finishing work (four items) and avoiding distraction (two items scored in reverse). The Cronbach's coefficient of the scale was 0.71 in this investigation.

\section{RESULTS}

\section{General Participants Characteristics}

Demographic and work-related characteristics and scores of presenteeism among 1,038 nurses are shown in Table 1. Among the 1,038 participants, $97.5 \%$ were female. The average age was $31.2 \pm 10.42$ years. The number of married people with children (60.9\%) was greater than unmarried ones (26.2\%) and married ones without children (12.9\%). Among the participants, senior nurses were the majority at $52.3 \%$, and $48.7 \%$ of the participants worked overtime once or twice a week. In the case of employment status, contractual (91.5\%) made up the majority. Nurses who earned 3,000-5,000 RMB were the majority at $60.4 \%$. 
TABLE 2 | Means, standard deviations, and correlations for all variables.

\begin{tabular}{|c|c|c|c|c|c|c|c|c|c|c|}
\hline Variables & Mean \pm SD & 1 & 2 & 3 & 4 & 5 & 6 & 7 & 8 & 9 \\
\hline SA & $23.37 \pm 6.84$ & 1 & & & & & & & & \\
\hline EED & $13.41 \pm 4.11$ & $0.395^{\star}$ & 1 & & & & & & & \\
\hline DA & $14.60 \pm 2.40$ & -0.019 & $0.179^{\star}$ & 1 & & & & & & \\
\hline EE & $20.21 \pm 11.42$ & $0.477^{\star}$ & $0.224^{*}$ & $-0.105^{\star}$ & 1 & & & & & \\
\hline D & $5.12 \pm 5.27$ & $0.467^{\star}$ & $0.228^{\star}$ & $-0.150^{\star}$ & $0.658^{\star}$ & 1 & & & & \\
\hline LPA & $15.15 \pm 10.73$ & $0.155^{\star}$ & -0.022 & $-0.384^{*}$ & $0.155^{\star}$ & $0.224^{*}$ & 1 & & & \\
\hline Emotional labor & $51.38 \pm 9.72$ & $0.865^{\star}$ & $0.745^{\star}$ & $0.309^{\star}$ & $0.404^{\star}$ & $0.388^{\star}$ & 0.005 & 1 & & \\
\hline Burnout & $40.47 \pm 20.39$ & $0.453^{\star}$ & $0.153^{\star}$ & $-0.326^{\star}$ & $0.784^{*}$ & $0.711^{*}$ & $0.726^{\star}$ & $0.329^{\star}$ & 1 & \\
\hline Presenteeism & $14.18 \pm 4.33$ & $0.301^{\star}$ & $0.212^{*}$ & $-0.139^{\star}$ & $0.482^{*}$ & $0.364^{*}$ & $0.160^{\star}$ & $0.442^{*}$ & $0.267^{\star}$ & 1 \\
\hline
\end{tabular}

$S A$, surface acting; $E E D$, emotionally expressed demands; $D A$, deep acting; $D$, depersonalization; EE, emotional exhaustion; $L P A$, low personal accomplishment. ${ }^{\star} P<0.01$.

TABLE 3 | Results of multivariable linear regression to predict presenteeism factors.

\begin{tabular}{|c|c|c|c|c|}
\hline Variable & $\beta$ & $t$ & $\boldsymbol{P}$ & VIF \\
\hline \multicolumn{5}{|l|}{ Gender (vs. male) } \\
\hline Female & 0.034 & 1.222 & 0.222 & 1.049 \\
\hline \multicolumn{5}{|l|}{ Age (vs. 20-30 years) } \\
\hline $30-40$ & 0.071 & 1.857 & 0.064 & 1.974 \\
\hline $40-50$ & 0.060 & 1.664 & 0.096 & 1.741 \\
\hline$>50$ & 0.046 & 2.067 & 0.039 & 1.112 \\
\hline \multicolumn{5}{|c|}{ Marital status (vs. unmarried) } \\
\hline Married without children & 0.004 & 0.139 & 0.890 & 1.367 \\
\hline Married with children & 0.016 & 0.393 & 0.694 & 2.147 \\
\hline \multicolumn{5}{|l|}{ Professional title (vs. nurse) } \\
\hline Senior nurse & 0.005 & 0.144 & 0.886 & 1.960 \\
\hline Nurse supervisor and above & 0.025 & 0.506 & 0.613 & 3.172 \\
\hline \multicolumn{5}{|l|}{ Weekly overtime (vs.0) } \\
\hline $1-2$ & 0.062 & 1.780 & 0.075 & 1.273 \\
\hline $3-4$ & 0.157 & 4.628 & 0.000 & 1.220 \\
\hline$>5$ & 0.120 & 3.760 & 0.000 & 1.093 \\
\hline \multicolumn{5}{|c|}{ Employment status (vs. permanent) } \\
\hline Contract & 0.018 & 0.560 & 0.576 & 1.396 \\
\hline \multicolumn{5}{|l|}{ Monthly income (vs. <3,000) } \\
\hline $3,000-5,000$ & 0.064 & 1.281 & 0.201 & 1.396 \\
\hline$>5,000$ & 0.047 & 0.884 & 0.377 & 3.333 \\
\hline Emotional labor & 0.214 & 7.063 & 0.000 & 1.154 \\
\hline Burnout & 0.407 & 13.415 & 0.000 & 1.233 \\
\hline
\end{tabular}

\section{Correlations Analysis Among Emotional Labor, Burnout, and Presenteeism}

Presenteeism was significantly positively correlated with surface acting, emotionally expressed demands, deep acting, emotion exhaustion, depersonalization, and low personal accomplishment $(P<0.01)$, according to correlation analysis. Notably, presenteeism had a significant negative association with deep acting $(P<0.01)$. Details can be found in Table 2.

\section{Multi-Variable Linear Regression}

The sociodemographic and job-related factors affecting presenteeism were predicted using multiple linear regression models. Presenteeism was explained by $22.8 \%$ of the variance in the final model as shown in Table $3(P<0.001)$. At the same time, more frequent weekly overtime and $>50$ years of age had predicted higher presenteeism in the regression model. The results also revealed that the higher the score of emotional labor and burnout, the more frequent the presenteeism.

\section{Measurement Model and Structural Equation Model}

Pearson's correlation coefficient for presenteeism, burnout subscales, and emotional labor subscales was used to create a measurement model with four latent constructs and three observable variables. To assess the model fit using the maximum likelihood estimate, confirmatory factor analysis was performed. The initial fit indices of the measurement model had indicated that the factor loading of personal accomplishment (observed variables of burnout) was $<0.5$, thus this variable was eliminated. Figure 2 depicts the measuring model. The measurement model was used to construct the structural model (Figure 3). The modification indices were used to correct the structural model, and the fit indices showed that the structural model with good fit was $C M I N / d f=1.371$, RMSEA $=0.019$, SRMR $=0.009$, AGFI $=0.991, \mathrm{CFI}=0.999$.

Table 4 displays the standardized estimates, critical ratio, standardizing effects, and mediating effect ratio for the route analysis. The direct impact on presenteeism was not significant ( $\beta=0.033, P=0.386$ ), but surface acting had a considerable effect on burnout $(\beta=0.542, P<0.001)$. On the other hand, surface acting had a substantial indirect influence on burnout $(\beta$ $=0.204, P<0.001)$. Burnout and presenteeism were significantly affected by emotionally expressed demands $(\beta=0.095, P=$ $0.004)$ and $(\beta=0.114, P=0.001)$. Burnout and presenteeism were negatively linked with deep acting $(\beta=-0.165, P=0.001)$ and $(\beta=-0.107, P=0.001)$. The indirect effects of emotionally expressed demands and deep acting on presenteeism were 0.036 and -0.064 , respectively. 


\section{DISCUSSION}

In this study, 1,038 in-care nurses from six tertiary-level hospitals in Shaanxi Province were studied via constructing a structural equation model to investigate the correlations

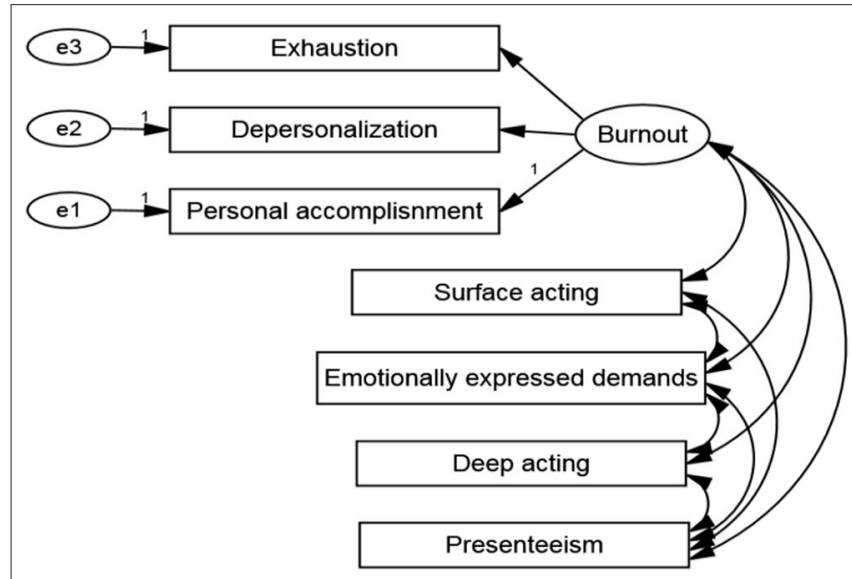

FIGURE 2 | The measurement model.

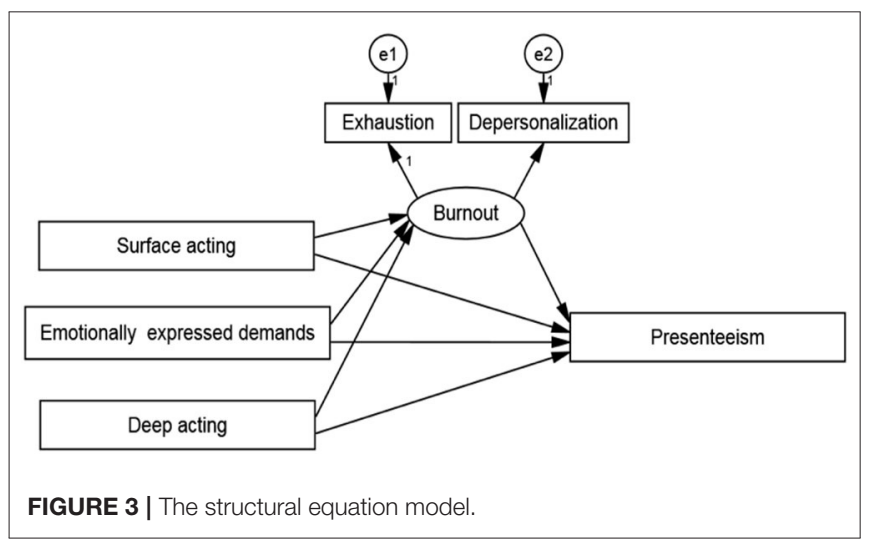

between three factors of emotional labor, burnout, and presenteeism. Deep acting alleviated burnout and reduced presenteeism directly, whereas emotionally expressed demands raised job burnout and presenteeism. Burnout played a completely mediating effect between surface acting and presenteeism.

First, the average presenteeism score was 14.18 (4.33). The SPS-6 score of China is greater than that of other countries (54). It may be related to the medical system of China. Nurses who work in public hospitals experienced more presenteeism (55). Health workers in China are extraordinarily overworked and have lower incomes than their counterparts in Europe and the United States (56). Multivariable linear regression carried out in this study has predicted demographic factors associated with presenteeism, and results revealed that higher presenteeism was predicted by more weekly overtime and $>50$ years of age. The results may be related to work stress, poor health, and organizational norms (55). It is noteworthy that presenteeism more likely occurred in older employees. Nurses with lengthy experience seemingly have a negative view of meeting workplace demands (8). Furthermore, nurses experience higher presenteeism with more frequent weekly over time, as previously reported (57). This suggested that managers should intervene to reduce presenteeism.

Second, this study examined the correlations between the research variables among the nurses. The Pearson's correlation coefficients for surface acting, emotionally expressed demands, emotion exhaustion, depersonalization, low personal accomplishment, and presenteeism were all significant. This study identified that deep acting and emotionally expressed demands directly and indirectly impacted the presenteeism of the nurses. Deep acting created an internal-external union that might result in favorable psychological states, which could expend limited resources on internalizing emotional expression and inner feeling (29, 58, 59). On the other hand, acting in good faith (deep acting) negatively affected presenteeism, congruent with a previous study (60). Therefore, nurse managers should be aware that deep acting emotion strategies could effectively reduce presenteeism. To improve

TABLE 4 | Standardized estimates, critical ratios, and standardized direct, indirect, and total effect and mediating effect ratio.

\begin{tabular}{|c|c|c|c|c|c|c|c|}
\hline $\begin{array}{l}\text { Endogenous } \\
\text { variable }\end{array}$ & Path & $\begin{array}{l}\text { Exogenous } \\
\text { variable }\end{array}$ & CR & Direct effect SE $(P)$ & $\begin{array}{l}\text { Indirect effect SE } \\
(P)\end{array}$ & Total effect SE $(P)$ & $\begin{array}{c}\text { Mediating } \\
\text { effect ratio (\%) }\end{array}$ \\
\hline \multirow[t]{3}{*}{ Burnout } & $\leftarrow$ & Surface acting & 15.121 & $0.542(<0.001)$ & & $0.542(<0.001)$ & \\
\hline & $\leftarrow$ & $\begin{array}{l}\text { Emotionally } \\
\text { expressed demands }\end{array}$ & 2.904 & $0.095(0.004)$ & & $0.095(0.004)$ & \\
\hline & $\leftarrow$ & Deep acting & -5.474 & $-0.165(<0.001)$ & & $-0.165(<0.001)$ & \\
\hline \multirow[t]{3}{*}{ Presenteeism } & $\leftarrow$ & Surface acting & 2.269 & $0.033(0.386)$ & $0.204(<0.001)$ & $0.236(<0.001)$ & 86.44 \\
\hline & $\leftarrow$ & $\begin{array}{l}\text { Emotionally } \\
\text { expressed demands }\end{array}$ & 3.59 & $0.114(0.001)$ & $0.036(0.005)$ & $0.150(<0.001)$ & 24.00 \\
\hline & $\leftarrow$ & Deep acting & -4.579 & $-0.107(<0.001)$ & $-0.064(<0.001)$ & $-0.169(<0.001)$ & 63.31 \\
\hline Presenteeism & $\leftarrow$ & Burnout & 10.367 & $0.438(<0.001)$ & & $0.376(<0.001)$ & \\
\hline
\end{tabular}

$\leftarrow$, Model pathway. 
the emotion management skills of the nurses, various research had indicated that self-training mindfulness, emotion therapy, empathy training, and educational training interventions can improve emotion regulation $(61,62)$. These interventions include self-emotional management, hospital management of caregivers, and organizational management. Emotion expression demands were also linked to greater burnout and presenteeism according to the study. It is difficult to compare our results to previous research because there are few studies in which emotionally expressed demands could predict presenteeism. The emotionally expressed demands are the particular behavior or emotion which mirrors the image of the nurse the hospital wishes to present. In turn, nurses remain courteous despite the patients make unreasonable demands (47). Undoubtedly, the requirements of the nursing profession had placed highwork demands on nurses. When nurses were constantly subjected to high expectations (for example, severe workload and emotional dissonance), they were positively linked to presenteeism (63). It should be noted that there is a lack of research indicating a link showing how emotionally expressed demands are related to presenteeism. Further study on this topic is necessary.

Surface acting did not directly influence presenteeism, which did not correspond with earlier research (30). The reason for this might be that, to our knowledge, this is the first study to construct a structural equation model to show the path association between the three emotional labor methods, burnout, and presenteeism in nurses. Furthermore, future studies should account for the confounding variables to explore the correlation between variables in this study.

In this study, we anticipated that burnout could mediate the effect of emotional labor techniques on presenteeism, and SEM has clarified this relationship. The structural equation model indicated that burnout has partially mediated the relationship between deep acting, emotionally expressed demands, and presenteeism, with a mediating effect of 24 and $63.31 \%$ of the total impact. Additional data also confirmed that job burnout played a complete mediating role in surface acting and presenteeism, with a mediating effect of $86.44 \%$. The risk of nurse emotional dissonance and lost productivity can be mitigated by relieving nurse burnout. A previous study revealed that nurses are required to display a particular expression at work that matches the requirements of the organization by expending resources according to the conservation of resources theory (64). The workload was also positively associated with presenteeism through higher burnout levels (36). Emotional dissonance caused by long-term surface acting and matching emotion expression demands will undoubtedly increase the emotional resources of the nurses, which only disappears after a lengthy recovery period. However, nurses must continue to work to meet high job demands, which disrupts the restoration process, causes chronic exhaustion, and leads to productivity loss. Given the shortage of nurses and presenteeism, hospital administrators should not force nurses to express the emotional labor required by the hospital in the face of rude or demanding patients (65). Burnout has been linked to dissatisfaction, missed care, self-compassion, and occupational turnover intention, according to studies $(48,66-$ 68). Furthermore, interventions to improve the ability of the nurses to regulate emotions in specific patient settings may prevent burnout and productivity loss.

Nevertheless, several limitations should be acknowledged. First, cross-sectional research resulted in insufficient data compared to a longitudinal design, which have drawn a causal association between emotional labor, burnout, and presenteeism. A subsequent longitudinal study will still have to evaluate the findings, and such linkages to inductive reasoning change the correlations between these variables. Secondly, our research participants comprised nurses from six hospitals but failed to consider the distinctions across the departments, such as in emergency, surgery, and critical care. In addition, the majority of research participants were women. Thus, further studies should analyze the disparities between nurse populations and gender. Third, only nurses from six hospitals in Xi'an city were chosen using convenience sampling. Although the representativeness of the sample was restricted, the structural equation model might be employed in future research to investigate the link between these variables using random sampling.

\section{CONCLUSION}

After investigating the demographic and job-related factors to predict presenteeism, we discovered that nurses who worked more overtime each week and were $>50$ years old were more likely to exhibit presenteeism. The nursing managers should reasonably arrange human resources, adjust shifts, reduce overtime work, and focus on nurses with rich experience. Different factors of emotional labor have different effects on presenteeism, according to the findings. Self-training mindfulness, emotion therapy, or other effective methods could improve the emotional management skills of the nurses and help them master the correct emotional labor strategies. The structural equation model verified our prediction that burnout acted as a mediator between diverse emotional labor techniques and presenteeism. Improving emotional management skills and alleviating burnout can reduce presenteeism. Nursing administrators should focus on alleviating the emotional exhaustion of nurses by reducing workload and increasing support among colleagues, among other methods.

\section{DATA AVAILABILITY STATEMENT}

The raw data supporting the conclusions of this article will be made available by the authors, without undue reservation.

\section{ETHICS STATEMENT}

The studies involving human participants were reviewed and approved by Affiliated Hospital of Shaanxi University of Traditional Chinese Medicine, Shaanxi Province, China. The 
patients/participants provided their written informed consent to participate in this study.

\section{AUTHOR CONTRIBUTIONS}

JS implemented this study and was responsible for data collection and analysis and writing. XL supported the investigation and data analysis. ZQ and RZ provided assistance in reviewing the

\section{REFERENCES}

1. Vîrgă D, Schaufeli WB, Taris TW, van Beek I, Sulea C. Attachment styles and employee performance: the mediating role of burnout. J Psychol. (2019) 153:383-401. doi: 10.1080/00223980.2018.1542375

2. Turpin RS, Ozminkowski RJ, Sharda CE, Collins JJ, Berger ML, Billotti GM, et al. Reliability and validity of the stanford presenteeism scale. J Occup Environ Med. (2004) 46:1123-33. doi: 10.1097/01.jom.0000144999.35675.a0

3. Schultz AB, Edington DW. Employee health and presenteeism: a systematic review. J Occup Rehabil. (2007) 17:547-79. doi: 10.1007/s10926-007-9096-x

4. Aronsson G, Gustafsson K. Sickness presenteeism: prevalence, attendancepressure factors, and an outline of a model for research. J Occup Environ Med. (2005) 47:958-66. doi: 10.1097/01.jom.0000177219.75677.17

5. McKevitt C, Morgan M, Dundas R, Holland WW. Sickness absence and 'working through' illness: a comparison of two professional groups. J Publ Health Med. (1997) 19:295-300. doi: 10.1093/oxfordjournals.pubmed.a024633

6. Rosvold EO, Bjertness E. Physicians who do not take sick leave: hazardous heroes? Scand J Publ Health. (2001) 29:71-5. doi: $10.1177 / 14034948010290010101$

7. Hansen CD, Andersen JH. Going ill to work-what personal circumstances, attitudes and work-related factors are associated with sickness presenteeism? Soc Sci Med. (2008) 67:956-64. doi: 10.1016/j.socscimed.2008.05.022

8. Li Y, Zhang J, Wang S, Guo S. The effect of presenteeism on productivity loss in nurses: the mediation of health and the moderation of general self-efficacy. Front Psychol. (2019) 10:1745. doi: 10.3389/fpsyg.2019.01745

9. Aysun K, Bayram S. Determining the level and cost of sickness presenteeism among hospital staff in Turkey. Int. J Occup. Saf. Ergon. (2017) 23:501-9. doi: 10.1080/10803548.2016.1274159

10. Kim J, Suh EE, Ju S, Choo H, Bae H, Choi H. Sickness experiences of korean registered nurses at work: a qualitative study on presenteeism. Asian Nurs Res. (2016) 10:32-8. doi: 10.1016/j.anr.2015.10.009

11. Letvak SA, Ruhm CJ, Gupta SN. Nurses' presenteeism and its effects on selfreported quality of care and costs. Am. J Nurs. (2012) 112:30-8; quiz: 48. doi: 10.1097/01.NAJ.0000411176.15696.f9

12. Aronsson G, Gustafsson K, Dallner M. Sick but yet at work. An empirical study of sickness presenteeism. J Epidemiol Commun Health. (2000) 54:502-9. doi: $10.1136 /$ jech.54.7.502

13. Martinez LF, Ferreira AI. Sick at work: presenteeism among nurses in a Portuguese public hospital. Stress Health. (2012) 28:297-304. doi: $10.1002 /$ smi. 1432

14. Allemann A, Siebenhüner K, Hämmig O. Predictors of presenteeism among hospital employees-a cross-sectional questionnaire-based study in Switzerland. J Occup Environ Med. (2019) 61:1004-10. doi: 10.1097/JOM.0000000000001721

15. Lui JNM, Andres EB, Johnston JM. Presenteeism exposures and outcomes amongst hospital doctors and nurses: a systematic review. BMC Health Serv Res. (2018) 18:985. doi: 10.1186/s12913-018-3789-Z

16. Yang T, Ma M, Zhu M, Liu Y, Chen Q, Zhang S, et al. Challenge or hindrance: does job stress affect presenteeism among Chinese healthcare workers? J Occup Health. (2018) 60:163-71. doi: 10.1539/joh.17-0195-OA

17. Taloyan M, Aronsson G, Leineweber C, Magnusson Hanson L, Alexanderson K, Westerlund H. Sickness presenteeism predicts suboptimal self-rated health and sickness absence: a nationally representative study of the Swedish working population. PLoS ONE. (2012) 7:e44721. doi: 10.1371/journal.pone.0044721 manuscript. FL guided the study design and interpretations. All authors approved the final paper.

\section{FUNDING}

The Shaanxi Provincial Department of Education 2018 Annual Special Scientific Research Program funded the study (No. 18JK0201).

18. Schmidt B, Schneider M, Seeger P, van Vianen A, Loerbroks A, Herr RM. A comparison of job stress models: associations with employee well-being, absenteeism, presenteeism, and resulting costs. J Occup Environ Med. (2019) 61:535-44. doi: 10.1097/JOM.0000000000001582

19. Schultz AB, Chen CY, Edington DW. The cost and impact of health conditions on presenteeism to employers: a review of the literature. PharmacoEconomics. (2009) 27:365-78. doi: 10.2165/00019053-200927050-00002

20. Widera E, Chang A, Chen HL. Presenteeism: a public health hazard. J Gen Intern Med. (2010) 25:1244-7. doi: 10.1007/s11606-010-1422-x

21. Rainbow JG, Drake DA, Steege LM. Nurse health, work environment, presenteeism and patient safety. Western J Nurs Res. (2020) 42:332-9. doi: 10.1177/0193945919863409

22. Grandey AA. Emotion regulation in the workplace: a new way to conceptualize emotional labor. J Occup Health Psychol. (2000) 5:95-110. doi: 10.1037/1076-8998.5.1.95

23. Maslach C, Leiter MP. Understanding the burnout experience: recent research and its implications for psychiatry. World Psychiatry. (2016) 15:103-11. doi: 10.1002/wps.20311

24. Maslach C, Schaufeli WB, Leiter MP. Job burnout. Annu Rev Psychol. (2001) 52:397-422. doi: 10.1146/annurev.psych.52.1.397

25. Yeh SJ, Chen SS, Yuan KS, Chou W, Wan TTH. Emotional labor in health care: the moderating roles of personality and the mediating role of sleep on job performance and satisfaction. Front Psychol. (2020) 11:574898. doi: $10.3389 /$ fpsyg.2020.574898

26. Yoon SL, Kim JH. Job-related stress, emotional labor, and depressive symptoms among Korean nurses. J Nurs Scholarsh. (2013) 45:169-76. doi: 10.1111/jnu.12018

27. Grandey AA, Melloy RC. The state of the heart: emotional labor as emotion regulation reviewed and revised. J Occup Health Psychol. (2017) 22:407-22. doi: 10.1037/ocp0000067

28. Kammeyer-Mueller JD, Rubenstein AL, Long DM, Odio MA, Buckman BR, Zhang Y, et al. A meta-analytic structural model of dispositonal affectivity and emotional labor. Person Psychol. (2013) 66:47-90. doi: 10.1111/peps.12009

29. Han SS, Han JW, Kim YH. Effect of nurses' emotional labor on customer orientation and service delivery: the mediating effects of work engagement and burnout. Saf Health Work. (2018) 9:441-6. doi: 10.1016/j.shaw.2017.12.001

30. Jung SW, Lee JH, Lee KJ. Assessing the association between emotional labor and presenteeism among nurses in Korea: cross-sectional study using the 4th Korean working conditions survey. Saf Health Work. (2020) 11:103-8. doi: 10.1016/j.shaw.2019.12.002

31. Younossi I, Weinstein A, Stepanova M, Hunt S, Younossi ZM. Mental and emotional impairment in patients with hepatitis $\mathrm{c}$ is related to lower work productivity. Psychosomatics. (2016) 57:82-8. doi: 10.1016/j.psym.2015. 10.005

32. Pei P, Lin G, Li G, Zhu Y, Xi X. The association between doctors' presenteeism and job burnout: a cross-sectional survey study in China. BMC Health Serv Res. (2020) 20:715. doi: 10.1186/s12913-020-05593-9

33. Rainbow JG, Gilbreath B, Steege LM. Risky business: a mediated model of antecedents and consequences of presenteeism in nursing. Nurs Res. (2020) 70:85-94. doi: 10.1097/NNR.0000000000000484

34. Vinod Nair A, McGregor A, Caputi P. The impact of challenge and hindrance demands on burnout, work engagement, and presenteeism. A cross-sectional study using the job demands-resources model. J Occup. Environ. Med. (2020) 62:e392-e7. doi: 10.1097/JOM.0000000000001908 
35. Bakker AB, Demerouti E, Verbeke W. Using the job demands-resources model to predict burnout and performance. Hum Resour Manage. (2010) 43:83-104. doi: 10.1002/hrm.20004

36. Bakker AB, Van Emmerik H, Van Riet P. How job demands, resources, and burnout predict objective performance: a constructive replication. Anxiety Stress Cop. (2008) 21:309-24. doi: 10.1080/10615800801958637

37. Demerouti E, Bakker AB, Nachreiner F, Schaufeli WB. The job demandsresources model of burnout. J Appl Psychol. (2001) 86:499-512. doi: 10.1037/0021-9010.86.3.499

38. Bakker AB, Demerouti E. Job demands-resources theory: taking stock and looking forward. J Occup Health Psychol. (2017) 22:273-85. doi: $10.1037 /$ ocp0000056

39. Rizo-Baeza M, Mendiola-Infante SV, Sepehri A, Palazón-Bru A, Gil-Guillén VF, Cortés-Castell E. Burnout syndrome in nurses working in palliative care units: an analysis of associated factors. J Nurs Manage. (2018) 26:19-25. doi: 10.1111 /jonm.12506

40. Miraglia M, Johns G. Going to work ill: a meta-analysis of the correlates of presenteeism and a dual-path model. J Occup Health Psychol. (2016) 21:261-83. doi: 10.1037/ocp0000015

41. Chambers M, Kantaris X, Guise V, Välimäki M. Managing and caring for distressed and disturbed service users: the thoughts and feelings experienced by a sample of English mental health nurses. J Psychiatr Ment Health Nurs. (2015) 22:289-97. doi: 10.1111/jpm.12199

42. Rafaeli A, Sutton RI. Expression of emotion as part of the work role. Acad Manage Rev. (1987) 12:23-37. doi: 10.5465/amr.1987.4306444

43. Thompson B. Ten commandments of structural equation modeling. In: Grimm LG, Yarnold PR, editors. Reading and Understanding MORE Multivariate Statistics. American Psychological Association (2000) p. 261-83.

44. Hu LT, Be Ntler PM. Fit indices in covariance structure modeling: Sensitivity to underparameterized model misspecification. Psychol Methods. (1998) 3:424-53. doi: 10.1037/1082-989X.3.4.424

45. Hu Lt, Bentler PM. Cutoff criteria for fit indexes in covariance structure analysis: Conventional criteria versus new alternatives. Struct Equat Model. (1999) 6:1-55. doi: 10.1080/10705519909540118

46. Grandey AA. When "the show must go on": surface acting and deep acting as determinants of emotional exhaustion and peer-rated service delivery. Acad Manage J. (2003) 46:86-96. doi: 10.5465/30040678

47. Luo H, Sun QL. Effect of emotional labor on professional burnout of nurses. Chinese J Nurs. (2008) 9:441-6. doi: 10.3761/j.issn.0254-1769.2008. 11.002

48. Xie Z, Wang A, Chen B. Nurse burnout and its association with occupational stress in a cross-sectional study in Shanghai. J Adv Nurs. (2011) 67:1537-46. doi: 10.1111/j.1365-2648.2010.05576.x

49. Wu S, Li H, Zhu W, Lin S, Chai W, Wang X. Effect of work stressors, personal strain, and coping resources on burnout in Chinese medical professionals: a structural equation model. Indus Health. (2012) 50:279-87. doi: 10.2486/indhealth.MS1250

50. Uchmanowicz I, Karniej P, Lisiak M, Chudiak A, Lomper K, Wiśnicka A, et al. The relationship between burnout, job satisfaction and the rationing of nursing care-A cross-sectional study. J Nurs Manage. (2020) 28:2185-95. doi: 10.1111 /jonm.13135

51. Hua YU. The application of Chinese version of maslach burnout inventory in Chinese nurses. J Nurs Sci. (2007) 24:50-52. doi: 10.3969/j.issn.1671-8283.2007.03.001

52. Zhao F, Dai JM, Yan SY. [Reliability and validity of Stanford Presenteeism Scale Chinese version]. Zhonghua lao dong wei sheng zhi ye bing za zhi $=$ Zhonghua laodong weisheng zhiyebing zazhi. Chin. J Indus. Hyg. Occup. Dis. (2010) 28:679-82. doi: 10.3760/cma.j.issn.1001-9391.2010. 09.012

53. Koopman C, Pelletier KR, Murray JF, Sharda CE, Berger ML, Turpin RS, et al. Stanford presenteeism scale: health status and employee productivity. J Occup Environ Med. (2002) 44:14-20. doi: 10.1097/00043764-20020100000004

54. Mosteiro-Díaz MP, Baldonedo-Mosteiro M, Borges E, Baptista P, Queirós C, Sánchez-Zaballos M, et al. Presenteeism in nurses: comparative study of5
Spanish, Portuguese and Brazilian nurses. Int Nurs Rev. (2020) 67:466-75. doi: 10.1111/inr.12615

55. Yang T, Ma M, Guo Y, Li Y, Tian H, Liu Y, et al. Do job stress, health, and presenteeism differ between Chinese healthcare workers in public and private hospitals: a cross sectional study. Psychol Health Med. (2020) 25:653-65. doi: 10.1080/13548506.2019.1668564

56. Yang T, Guo Y, Ma M, Li Y, Tian H, Deng J. Job stress and presenteeism among chinese healthcare workers: the mediating effects of affective commitment. Int J Environ Res Publ Health. (2017) 14:978. doi: 10.3390/ijerph14090978

57. Park JW, Cho SS, Lee J, Hwang J, Kim JI, Kim BG, et al. Association between employment status and sickness presenteeism among Korean employees: a cross-sectional study. Ann Occup Environ Med. (2020) 32:e17. doi: 10.35371/aoem.2020.32.e17

58. Peng J, He Y, Deng J, Zheng L, Chang Y, Liu X. Emotional labor strategies and job burnout in preschool teachers: psychological capital as a mediator and moderator. Work. (2019) 63:335-45. doi: 10.3233/WOR-192939

59. Deng H, Wu H, Qi X, Jin C, Li J. Stress reactivity influences the relationship between emotional labor strategies and job burnouts among Chinese hospital nurses. Neural Plast. (2020) 2020:8837024. doi: 10.1155/2020/8837024

60. Hülsheger UR, Lang JW, Maier GW. Emotional labor, strain, and performance: testing reciprocal relationships in a longitudinal panel study. $J$ Occup Health Psychol. (2010) 15:505-21. doi: 10.1037/a0021003

61. Hülsheger UR, Alberts HJ, Feinholdt A, Lang JW. Benefits of mindfulness at work: the role of mindfulness in emotion regulation, emotional exhaustion, and job satisfaction. J Appl Psychol. (2013) 98:310-25. doi: 10.1037/a0031313

62. SUN SLX. Research progress on intervention management of emotional labor in nurses. Chinese J Nurs. (2021) 56:137-42. doi: 10.3761/j.issn.0254-1769.2021.01.023

63. Gillet N, Huyghebaert-Zouaghi T, Réveillère C, Colombat P, Fouquereau E. The effects of job demands on nurses' burnout and presenteeism through sleep quality and relaxation. J Clin Nurs. (2020) 29:583-92. doi: 10.1111/jocn.15116

64. Brotheridge CM, Lee RT. Testing a conservation of resources model of the dynamics of emotional labor. J Occup Health Psychol. (2002) 7:57-67. doi: 10.1037/1076-8998.7.1.57

65. Picardo JM, López-Fernández C, Hervás MJ. The Spanish version of the emotional labour scale (ELS): a validation study. Nurse Educ Today. (2013) 33:1130-5. doi: 10.1016/j.nedt.2012.12.008

66. Clark R, Lake E. Burnout, job dissatisfaction and missed care among maternity nurses. J Nurs Manage. (2020) 28:2001-6. doi: 10.1111/jonm.13037

67. Vaillancourt ES, Wasylkiw L. The intermediary role of burnout in the relationship between self-compassion and job satisfaction among nurses. Can J Nurs Res. (2019). doi: 10.1177/0844562119846274

68. Van der Heijden B, Brown Mahoney C, Xu Y. Impact of job demands and resources on nurses' burnout and occupational turnover intention towards an age-moderated mediation model for the nursing profession. Int J Environ Res Publ Health. (2019) 16:2011. doi: 10.3390/ijerph16112011

Conflict of Interest: The authors declare that the research was conducted in the absence of any commercial or financial relationships that could be construed as a potential conflict of interest.

Publisher's Note: All claims expressed in this article are solely those of the authors and do not necessarily represent those of their affiliated organizations, or those of the publisher, the editors and the reviewers. Any product that may be evaluated in this article, or claim that may be made by its manufacturer, is not guaranteed or endorsed by the publisher.

Copyright (c) 2021 Song, Liu, Li, Qu, Zhang and Yao. This is an open-access article distributed under the terms of the Creative Commons Attribution License (CC BY). The use, distribution or reproduction in other forums is permitted, provided the original author(s) and the copyright owner(s) are credited and that the original publication in this journal is cited, in accordance with accepted academic practice. No use, distribution or reproduction is permitted which does not comply with these terms. 